\title{
Datos geográficos abiertos para la conservación preventiva del patrimonio arquitectónico
}

\author{
Emilio J. Mascort-Albea | Escuela Técnica Superior de Arquitectura, Universidad de Sevilla
}

URL de la contribución <www.iaph.es/revistaph/index.php/revistaph/article/view/3948>

El elevado protagonismo que han adquirido los datos abiertos en la toma de decisiones técnicas se está haciendo cada vez más patente en aquellos campos de actuación que se relacionan con disciplinas como la gestión del desarrollo territorial, el urbanismo o la arquitectura (LAS CASAS; LOMBARDO; MURGANTE et ál., 2016). A su vez, los bienes patrimoniales de carácter material cada vez se encuentran mejor contextualizados gracias a la información que se publica periódicamente en los portales institucionales.

Es precisamente en este punto donde las infraestructuras de datos espaciales (IDE) adquieren una notable importancia. A través de este tipo de portales, la información geográfica se puede compartir de múltiples maneras, entre las que destacan la visualización del dato y la descarga del mismo. Sin embargo, a lo largo de este complejo proceso se debe tener en cuenta la existencia de estándares y normativas que regulan su uso, así como la exigencia de unas determinadas condiciones de interoperabilidad para los servicios publicados. A su vez, la elaboración de productos que integren los mapas interactivos en aplicaciones informáticas constituye una vía que permite acercar los datos a la ciudanía. En los últimos años ha quedado demostrado que su uso en temáticas de difusión patrimonial encierra un elevado número de posibilidades (MASCORT-ALBEA; RUIZ-JARAMILLO; LÓPEZ LARRÍNAGA et ál. 2016).

Por otro lado, podemos afirmar que la espacialidad es una componente esencial de la arquitectura, y todo aquel formato que sea capaz de asumirla se convierte en un medio válido para almacenar información arquitectónica. En este sentido, consideramos que el dato geográfico, habitualmente empleado en las plataformas institucionales, encierra un elevado potencial para construir modelos de conocimiento que integren la informa-

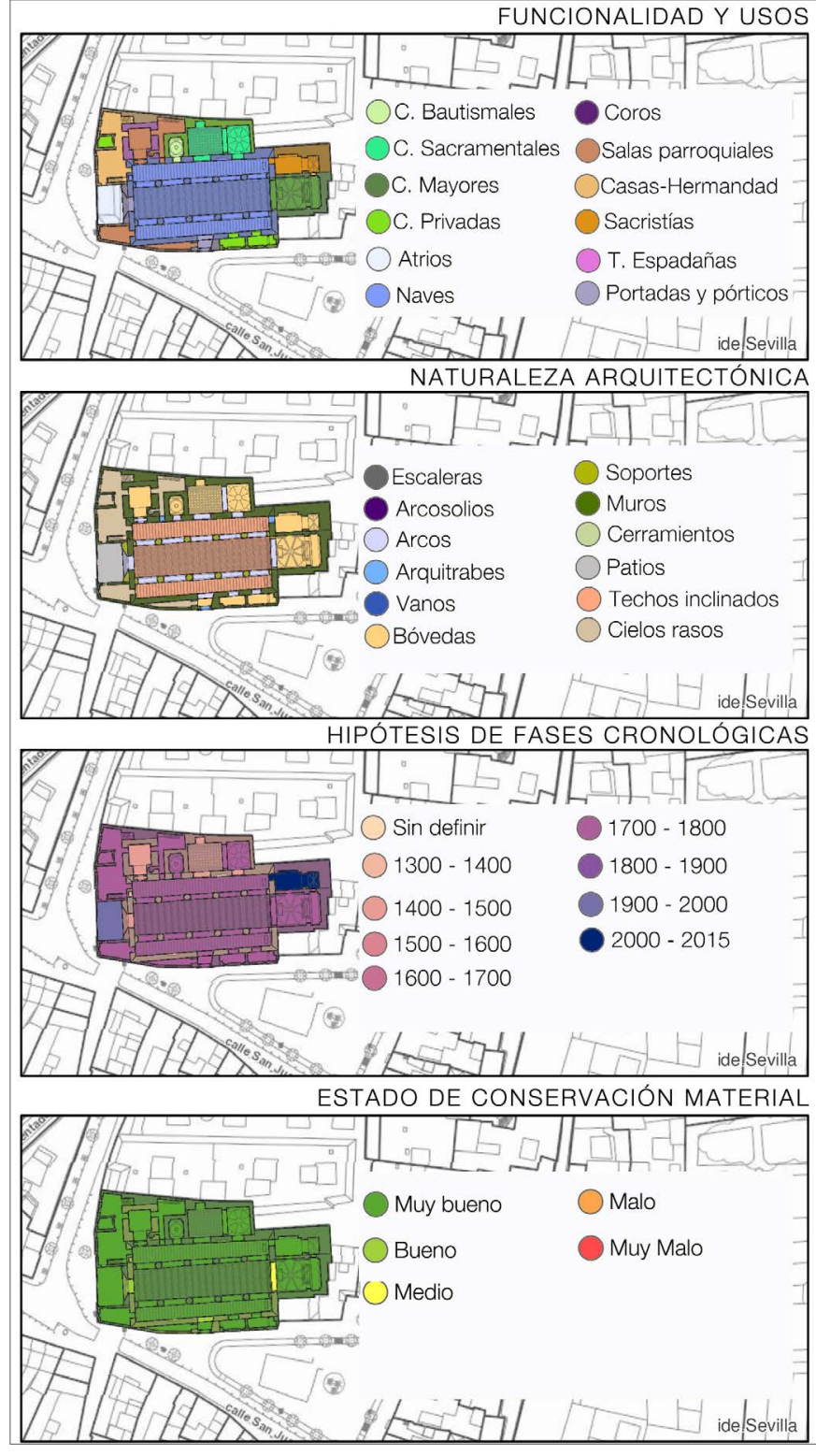

Parámetros de información relativos al estado actual de la iglesia de San Juan de la Palma (Sevilla), gestionados y publicados mediante sistemas de información geográfica (SIG) | elaboración propia a partir de base cartográfica publicada por IDE.Sevilla 
ción arquitectónica dentro del extenso panorama que construyen los actuales sistemas cartográficos.

De este modo, resulta fácil encontrar datos macroscópicos y territoriales capaces de contextualizar el bien arquitectónico a través de cuestiones tan relevantes para su conservación preventiva como son los riesgos naturales, las condiciones ambientales, los niveles de contaminación, la naturaleza del terreno y/o las afecciones normativas. Sin embargo, este tipo de información suele ser más limitada cuando se alcanza un nivel de detalle más próximo al propio bien patrimonial. Y es precisamente en el grado de resolución cartográfica que alcanza el detalle arquitectónico donde se ha detectado un vacío de contenidos que encierra un gran potencial. La información geográfica que este tipo de portales proporciona suele ser muy escasa; esta circunstancia se suele manifestar en el bajo nivel de representación arquitectónica que poseen las bases cartográficas institucionales.

Por tanto, se considera que la construcción de la información geográfica a escala arquitectónica es una tarea

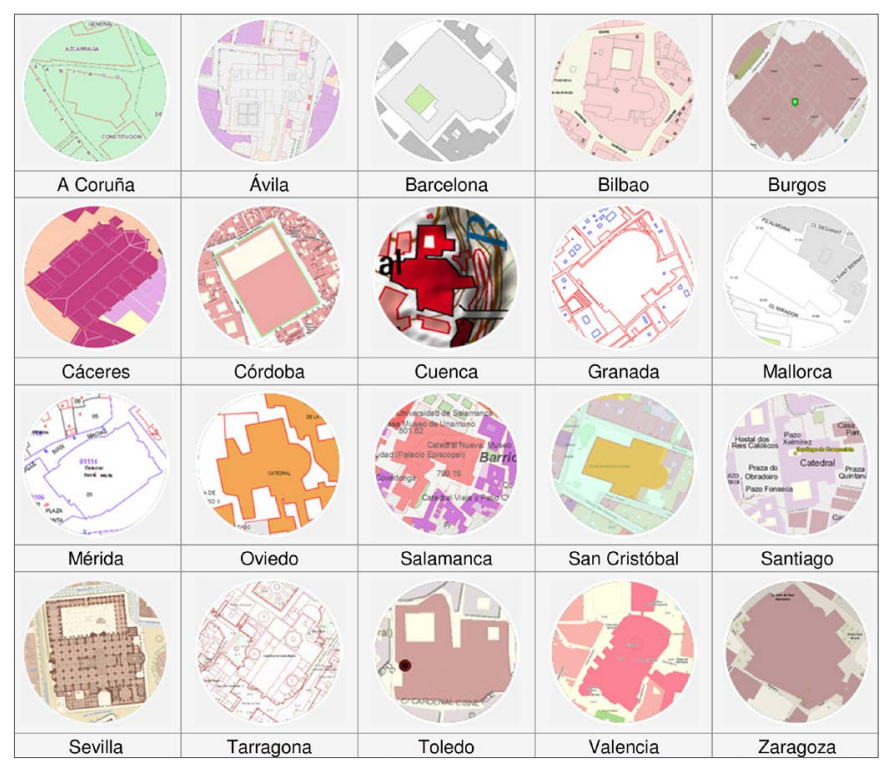

Resolución cartográfica a escala arquitectónica en ciudades españolas con sitios declarados Patrimonio Mundial por la UNESCO | elaboración propia a partir de red de portales geográficos de la Infraestructura de Datos Espaciales de España necesaria que debe ser realizada de forma colectiva, y que debe repercutir en las tareas de preservación que afectan a la arquitectura patrimonial. A su vez, esa información compartida mediante políticas de datos abiertos puede constituir un aliciente más para el desarrollo de iniciativas que permitan un mayor y mejor conocimiento del patrimonio a través del uso de mapas interactivos que nos permitan profundizar en la naturaleza de los edificios patrimoniales, así como en la de los bienes muebles que se localicen en su interior.

\section{BIBLIOGRAFÍA}

- LAS CASAS, G.; LOMBARDO, S.; MURGANTE, B. et ál. (2014) Open Data for Territorial Specialization Assessment. Territorial Specialization in Attracting Local Development Funds: an Assessment. Procedure Based on Open Data and Open Tools. Tema. Journal of Land Use, Mobility and Environment, n. ${ }^{\circ}$ especial, 2014, pp. 581-595 <http://www.tema.unina.it/ index.php/tema/article/view/2557> [Consulta: 15/06/2017]

- MASCORT-ALBEA, E. J.; RUIZ-JARAMILLO, J.; LÓPEZ LARRÍNAGA, F. et ál. (2016) Sevilla, Patrimonio Mundial: guía cultural interactiva para dispositivos móviles. Revista $\mathrm{PH}, \mathrm{n} .^{\circ}$ 90, 2016, pp. 152-168 <http://www.iaph.es/revistaph/index. php/revistaph/article/view/3778> [Consulta: 15/06/ 2017] 